\title{
A necessária indomesticabilidade de termos como "Antropoceno": desafios epistemológicos e ontologia relacional
}

\section{The necessary untameability of terms as "the Anthropocene": epistemological challenges and relational ontology}

Renzo Taddei ${ }^{1}$

Davide Scarso ${ }^{2}$

Nuno Pereira Castanheira3

\section{Resumo}

Nesta entrevista, realizada por Davide Scarso e Nuno Pereira Castanheira entre os meses de novembro e dezembro de 2020 via e-mail, o Professor Renzo Taddei (Unifesp) discute o significado do termo Antropoceno e as suas implicações, com base nas contribuições teóricas de Deborah Danowski, Eduardo Viveiros de Castro, Donna Haraway, Isabelle Stengers e Bruno Latour, entre outros. O entrevistado enfatiza a necessidade de evitarmos a redução do Antropoceno ou termos similares a conceitos científicos, assim preservando a sua capacidade indutora de novas perspectivas e transformações existenciais e resistindo à tentação de objetivação dominadora de um mundo mais complexo e bagunçado do que a epistemologia clássica gostaria de admitir.

Palavras-chave: Ecologia. Sustentabilidade. Ontologia. Epistemologia. Política

\footnotetext{
1 Professor de Antropologia da Universidade Federal de São Paulo (Unifesp). Orcid ID: https://orcid.org/oooo-0002-9935-6183.

E-mail: renzo.taddei@unifesp.br

2 Professor no Departamento de Ciências Sociais Aplicadas da Faculdade de Ciências e Tecnologia da Universidade Nova de Lisboa (FCT-UNL). Orcid ID: https://orcid.org/oooo-0oo3-1111-1286.

E-mail: d.scarso@fct.unl.pt

3 Pesquisador PNPD/CAPES e Professor-Colaborador no Programa de Pós-Graduação em Filosofia da Pontifícia Universidade Católica do Rio Grande do Sul - PUCRS. Orcid ID: https://orcid.org/oooo-0003-3295-9454.

E-mail: npcastanheira@gmail.com
} 


\title{
2 | Dossiê - Natureza e Sociedade no Antropoceno - Superando a Separação?
}

\begin{abstract}
In this interview, conducted via e-mail by Davide Scarso and Nuno Pereira Castanheira between the months of November and December 2020, Professor Renzo Taddei (Unifesp) discusses the meaning of the term Anthropocene and its implications, based on the theoretical contributions of Deborah Danowski, Eduardo Viveiros de Castro, Donna Haraway, Isabelle Stengers and Bruno Latour, among others. The interviewee emphasizes the need of avoiding the reduction of the Anthropocene and similar terms to scientific concepts, thus preserving their ability to induce new perspectives and existential transformation, and resisting the temptation of objectifying domination of a world that is more complex and messier than classical epistemology would like to acknowledge.
\end{abstract}

Keywords: Ecology. Sustainability. Ontology. Epistemology. Politics.

\section{1) O que exatamente é o Antropoceno: um conceito científico, uma proposição política, um alarme soando?}

Esta questão é tema de amplos e acalorados debates. Uma coisa que parece estar clara, no entanto, é que não há lugar para o advérbio "exatamente" nas muitas formas como o Antropoceno é conceitualizado. De certa maneira, o contexto em que a questão é colocada define suas respostas potenciais. Sugerir um nome que aponte para os sintomas do problema é distinto de tentar circunscrever as suas causas, e ambas as coisas não são equivalentes ao intento de atribuir responsabilidades. $\mathrm{O}$ problema é que o Antropoceno pode ser lido como qualquer uma destas coisas, e isso causa desentendimentos. É neste contexto que surgem argumentos em defesa do uso dos termos Capitaloceno ou Plantationceno 4 , dentre outros, como alternativas mais apropriadas. O anthropos do Antropoceno sugere uma humanidade tomada de forma geral, sem atentar para a quantidade de injustiça e racismo ambientais na conformação do contexto presente.

Todos estes nomes têm sua utilidade, mas devem ser usados com cuidado. Como mostraram, cada qual à sua maneira, Timothy Morton 5 e Deborah Danowski e Eduardo Viveiros de Castro $^{6}$ em colaboração, não somos capazes de abarcar o

\footnotetext{
4 Haraway, Donna. "Anthropocene, capitalocene, plantationocene, chthulucene: Making kin." Environmental humanities 6.1 (2015): 159-165.

5 Morton, Timothy. Hyperobjects: Philosophy and Ecology after the End of the World. U of Minnesota Press, 2013.

${ }^{6}$ Danowski, Déborah, and Eduardo Viveiros de Castro. Há mundo por vir? Ensaio sobre os medos e os fins. Cultura e Barbárie Editora, 2014.
} 
problema em sua totalidade. É um marco importante na história do pensamento social e filosófico que efetivamente exista certo consenso de que o problema é maior e mais complexo que nossos sistemas conceituais e nossas categorias de pensamento. O que nos resta é fazer uso produtivo, na forma de bricolagem, das ferramentas conceituais imperfeitas que possuímos. Como Donna Haraway afirmou repetidamente por toda a sua carreira, o mundo real é mais complexo e bagunçado ("messy") do que tendemos a reconhecer. Todas as teorias científicas são modelos de arame, e isto inclui, obviamente, as das ciências sociais. Não seria diferente no que diz respeito ao Antropoceno.

No fundo, a busca sôfrega pelo termo "correto" é um sintoma do problema de como nossas mentes estão colonizadas por ideias positivistas sobre a realidade. Em geral, tendemos a cair muito rápido na armadilha de sentir que, quando temos um nome para algo, entendemos do que se trata. Via de regra, trata-se do oposto: nomes estão associados a formas de regimentação semiótica do mundo; são parte de nossos esforços de domesticação da realidade, de tentativa de reduzi-la a nossas expectativas sobre ela. Este é especialmente o caso de nomes "taxonômicos", como o Antropoceno: são molduras totalizantes que direcionam nossa atenção a certas dimensões do mundo, produzidas pelas ideias hegemônicas do lugar e do tempo em que estão em voga. Há muitas maneiras de desarmar esse esquema; uma é apontando para o fato de que pensar um mundo feito de "objetos" ou mesmo "fenômenos" é causa e efeito, ao mesmo tempo, do fato de que as ciências buscam, em geral, causas unitárias para efeitos específicos no mundo. Isso funciona para a física newtoniana mas não funciona para o que chamamos de ecossistemas, por exemplo. A existência mesma do hábito de criar coisas como o termo Antropoceno nos impede de abordar de forma produtiva o problema que o termo tenta descrever. O termo é, desta forma, uma tentativa de objetificação; o que ele acaba objetificando são alguns de nossos medos e ansiedades. Dado que temos muito a temer, e tememos de formas muito diversas, não é surpresa que inexista consenso a respeito do que é o Antropoceno.

Se um nome se faz necessário, precisamos de um que faça coisas outras que reduzir nossa ansiedade cognitiva a níveis administráveis. Esta é a forma, lembremos, como Latour definiu a produção da “verdade" no âmbito das ciências7. Ou seja, o que estou

\footnotetext{
7 Latour, Bruno, and Steve Woolgar. A vida de laboratório: a produção dos fatos científicos. Rio de Janeiro: Relume Dumará, 1997
} 


\section{4 | Dossiê - Natureza e Sociedade no Antropoceno - Superando a Separação?}

dizendo é que o Antropoceno, ou qualquer outro termo que usemos em seu lugar, para ser útil de alguma forma, não deve ser um conceito científico. Necessitamos de um termo que desestabilize nossos esquemas conceituais e nos induza a novas perspectivas e à transformação de nossos modos de existência. Um conceito desta natureza deve ser, necessariamente, indomesticável. Deve, portanto, resistir ao próprio ímpeto definidor da cognição. Etimologicamente, definir é delimitar, colocar limites; trata-se, portanto, de uma forma de domesticação. Um conceito indomesticável será, necessariamente, desconfortável; será percebido como "confusão".

Na minha percepção, essa é uma das dimensões do conceito de Chthuluceno, proposto por Donna Haraway8 ${ }^{8}$ Ele não nos fala sobre o que supostamente está acontecendo com o mundo, mas propõe, ao mesmo tempo e de forma sobreposta, novas maneiras de entender as relações entre os seres e o poder de constituição de mundos de tais relações, onde o humano e o próprio pensamento são frutos de processos simpoiéticos. Esta perspectiva impossibilita a adoção, mesmo que tácita e por hábito, da ideia de humano herdada do iluminismo e do liberalismo europeus como elemento definidor da condição que vivemos no Antropoceno, e desarticula o especismo embutido em tais perspectivas.

Outra dimensão fundamental associada ao conceito de Chthuluceno é sua rejeição das metafísicas totalizantes, onde ideias abstratas tem a pretensão de ser universais e, portanto, de não ter ancoragem contextual. Haraway sugere que precisamos alterar nossa perspectiva a respeito do que é importante, em direção ao que ela chama de materialismo sensível em contextos simpoiéticos: a capacidade de perceber as relações que constituem a vida, nos contextos locais, e de agir de forma responsável sobre tais relações. Toda forma de conhecimento é parcial, fragmentada, e tem marcas de nascimento. Quando o conhecimento se apresenta sem o reconhecimento explícito dessas coisas, uma de duas alternativas está em curso: os envolvidos reconhecem e aceitam essa incontornável contextualidade do saber e isso não é mais uma questão; ou o conhecimento segue parte das engrenagens do colonialismo.

\footnotetext{
${ }^{8}$ Haraway, D. 2016. Staying with the Trouble: Making Kin in the Chthulucene. Durham: Duke University Press.
} 
A ideia de aterramento, apresentada no último livro de Latour ${ }^{9}$, converge em grande medida com as posições de Haraway. Em termos de tradições filosóficas, na minha percepção de não-especialista parece-me que ambos se alinham com o pragmatismo norte-americano, ainda que raramente façam referência a isso.

\section{2) Frequentemente, quando se discutem os problemas ambientais mais críticos do presente, mas também outros temas urgentes da contemporaneidade, a falta de unanimidade e consenso é lamentada. $O$ que seria, à luz de sua pesquisa e reflexão, uma resposta "adequada" às muitas questões difíceis colocadas pelo Antropoceno?}

Vivemos em tempos complexos, e o desenvolvimento das ferramentas conceituais disponíveis para dar conta do que temos adiante de nós segue em ritmo acelerado, mas não exatamente na direção do que as ideologias de progresso científico do século 20 supunham natural. Não me parece que estamos chegando "mais perto" de algo que sejamos capazes de chamar de "solução", ainda que filosófica. Não se trata mais disso. O que os autores inseridos nos debates sobre o Antropoceno estão sugerindo é que este ideário de progresso colapsou filosoficamente, ainda que siga sendo conveniente ao capitalismo. A maior parte da academia segue trabalhando dentro deste paradigma falido, de forma inercial ou porque efetivamente atua para fornecer recursos ao capitalismo.

O que ocorre é que as noções de que a mente tem acesso imediato à realidade e de que as ideias explicativas sobre o mundo buscam uma ordem subjacente universal, da qual as coisas e contextos são apenas reflexos imperfeitos - uma ordem platônica, portanto - vêm sendo atacadas desde pelo menos Nietzsche. Os autores mais importantes do debate do Antropoceno são herdeiros de uma corrente perspectivista do século 20 que tinha Nietzsche em posição central, mas que incluía também Whitehead e James, e que posteriormente esteve ligada principalmente a Deleuze e Foucault. Isso explica o fato de que é parte fundamental do debate sobre o Antropoceno a crítica às filosofias de transcendência e a atenção dada à questão das relações de imanência. É contribuição fundamental de Eduardo Viveiros de Castro mostrar ao mundo que o que Deleuze entendia como imanência tinha

\footnotetext{
9 Latour, Bruno. Onde aterrar? Rio de Janeiro: Bazar do Tempo, 2020.
} 


\section{6 | Dossiê - Natureza e Sociedade no Antropoceno - Superando a Separação?}

relações profundas com o pensamento indígena amazônico ${ }^{10}$, e ele estava trabalhando nisso muito antes da questão do Antropoceno se impor na filosofia e nas ciências sociais. Quando o Antropoceno se tornou tema incontornável, a questão dos modos de vida indígenas ganhou saliência não apenas por se apresentar como forma real, empírica de se viver de modos relacionais, mas também pelo fato de que os povos indígenas têm pegada de carbono zero e promovem a biodiversidade. Este último item funciona como ponte entre os debates mais propriamente filosóficos e os ecológicos.

Isso tudo me parece importante para falarmos sobre o que são, e que expectativas existem em torno dos temas de unanimidade e consenso. O desejo da comunicação perfeita é irmão gêmeo do desejo da nomeação perfeita, citado na resposta anterior. Em ambos os casos, trata-se da manifestação de uma concepção de mente que flutua no vácuo, desconectada das bases materiais e processuais que a fazem existir. De certa forma, esta concepção subjaz aos debates sobre o dissenso sempre que este é entendido como problema epistemológico. Quando isso ocorre, a intersubjetividade entendida como necessária ao processo de construção de consenso é vista como ligada a conceitos e ideias, e os diagnósticos sobre a razão do dissenso rapidamente caem nas valas comuns da "falta de educação" ou de "formas míticas de pensamento".

A despeito das diferenças entre os autores associados ao debate sobre o Antropoceno - Haraway, Latour, Viveiros de Castro, Stengers, dentre muitos outros -, uma das coisas que todos têm em comum é a rejeição de uma abordagem que reduz o problema a uma questão epistemológica, em favor de uma perspectiva que dá centralidade à dimensão mais propriamente ontológica. Em razão disso, intercâmbios muito frutíferos passaram a ocorrer entre a filosofia e a antropologia, como se pode ver na obra não apenas do Viveiros de Castro, mas também de Tim Ingold, Elizabeth Povinelli, Anna Tsing, e muitos outros.

A questão aqui é que, quando as questões ontológicas, dentro de filosofias relacionais e perspectivísticas, passam a ser tomadas em conta, a comunicação passa a ser outra coisa. O exemplo mais bem acabado de teorização sobre isso é a teoria do perspectivismo ameríndio ${ }^{11}$, desenvolvida por Viveiros de Castro e por

\footnotetext{
${ }^{10}$ Viveiros de Castro, Eduardo. Metafísicas canibais. São Paulo: Cosac Naify, 2015.

${ }^{11}$ Viveiros de Castro, Eduardo. "Perspectivismo e multi-naturalismo na América indígena." In: A inconstância da alma selvagem e outros ensaios de antropologia. São Paulo: Cosac Naify, 2002: 345399.
}

Opinião Filosófica - ISSN: 2178-1176 - Editora Fundação Fênix. www.fundarfenix.com.br 
Tania Stolze Lima. Esta teoria postula que o que os seres percebem no mundo é definido pelo tipo de corpos que têm, dentro de relações interespecíficas perigosas (de predação, por exemplo), e frente a um pano de fundo cosmológico em que grande parte dos seres têm consciência e intencionalidade equivalentes às humanas. Para alguns povos, por exemplo, a onça vê o humano como porco do mato e sangue como cerveja de caium, enquanto o porco do mato vê o humano como onça. A questão crucial, aqui, é que nenhuma das visões é ontologicamente superior à outra. Isso quer dizer que percepção humana não é mais "correta” que a da onça; é simplesmente produzida por um corpo humano, enquanto a da onça é produzida por um corpo de onça. Não há perspectiva absoluta, porque não corpo absoluto. Como é que onça e humano se comunicam, então? A pergunta é interessante logo de saída, porque entre os ocidentais a onça é tida como irracional e destituída de linguagem, e a comunicação é entendida como impossível. Nos mundos indígenas, geralmente cabe ao xamã, através de tecnologias xamânicas - que na Amazônia costuma implicar o uso de substâncias das plantas da floresta -, sair de seu corpo de humano e entrar em contato com o espírito da onça, ou dos seres de alguma forma associados às onças. Mas essa é apenas parte da questão; a relação entre caçador e presa, mais ordinária do que o contexto xamânico, é frequentemente descrita como relação de sedução, como uma forma de coreografia entre os corpos.

Alguns autores do debate sobre o Antropoceno têm explorado as implicações filosóficas de uma nova fronteira da microbiologia que apresenta os seres e seus corpos através de outras lentes. Em seu último livro, Haraway discute o conceito de holobionte, um emaranhado de seres em relações simbióticas que permitem a ocorrência da vida dos envolvidos. A questão filosófica importante que advém dos holobiontes é que, ao invés de falarmos de seres que estão em simbiose, parece mais apropriado dizer que é a partir das relações que emergem os seres. A simbiose é anterior aos seres, por assim dizer. Isso pode parecer muito técnico, e fica mais claro se mencionarmos que o corpo humano é entendido como um holobionte. O corpo existe em relação de simbiose com um número imenso de bactérias e outros seres, como fungos e vírus, e está bem documentado que as bactérias que habitam o trato intestinal humano têm efeito sobre o funcionamento do sistema nervoso, induzindo a pessoa a certos estados de ânimo e vontades. Esticando o argumento no limite da provocação, seria possível dizer que o que chamamos de consciência não é produzido nas células que têm o "nosso" DNA, mas é um fenômeno emergente da 


\section{8 | Dossiê - Natureza e Sociedade no Antropoceno - Superando a Separação?}

associação simbiótica entre os sistemas do corpo humano e os demais seres que compõe o holobionte.

Se for este o caso, a comunicação não se dá entre mentes e sistemas semióticos imateriais, mas entre seres imbuídos de sua materialidade e da materialidade dos contextos em que vivem. Mais do que pensar de forma alinhada, a questão passa a ser encontrar formas de relação que, como diz Haraway, nos permita viver e morrer bem em simpoiese com os demais seres. Como coloquei em outro lugar ${ }^{12}$, precisamos ser capazes de fazer alianças com quem não pensa como pensamos, com quem não pensa como humanos, e com que não pensa.

O problema é imensamente maior que o do consenso, e ao mesmo tempo mais realista, em termos das possibilidades de materialização de soluções. Duas formas de abordagem da questão foram desenvolvidas entre antropólogos que trabalham na Amazônia: Viveiros de Castro propôs a teoria do equívoco controlado ${ }^{13}$, e Mauro Almeida a dos encontros pragmáticos ${ }^{14}$. Ambos os casos se referem à comunicação de seres que existem em mundos distintos, ou seja, suas existências são compostas de acordo com pressupostos distintos sobre o que existe e o que significa existir. É imediato pensar no contexto do contato entre povos indígenas e não indígenas, mas o esquema pode ser usado para pensar qualquer relação de diferença. A ideia de que a comunicação pressupõe necessariamente o alinhamento epistemológico, nesta perspectiva, implica processos de violência contra corpos, culturas e mundos.

Basta olharmos a nosso redor para perceber que a vida comum não pressupõe alinhamento epistemológico. Há alguns dias vi um grupo de formigas cooperando para carregar uma migalha de pão muito maior do que o corpo de cada uma delas, e estavam subindo uma parede vertical. Fiquei espantado com a capacidade de cooperação entre seres entre os quais não existe atividade epistemológica. Entre os seres que pensam, boa parte do que existe no mundo é fruto de desentendimentos produtivos - uma pessoa diz uma coisa, a outra entende algo diferente, e juntas transformam a sua realidade, sem serem capazes sequer de avaliar de forma idêntica o resultado de suas ações, mas ainda assim podendo ambas sentirem-se

\footnotetext{
12 Taddei, Renzo. "No que está por vir, seremos todos filósofos-engenheiros-dançarinos ou não seremos nada." Moringa 10.2 (2019): 65-90.

13 Viveiros de Castro, Eduardo. 2004. "Perspectival Anthropology and the Method of Controlled Equivocation." Tipití: Journal of the Society for the Anthropology of Lowland South America 2 (1): 1.

14 Almeida, Mauro William Barbosa. Caipora e outros conflitos ontológicos. Revista de Antropologia da UFSCar, v. 5, n. 1, p.7-28, 2013
} 
satisfeitas com o processo. É como se estivessem dançando: nunca se dança da mesma forma, ainda que os corpos estejam conectados, e tampouco se entende o que se está fazendo da mesma forma durante a performance da dança, e com tudo isso é perfeitamente possível que o efeito seja o sentimento de satisfação e a fruição estético-afetiva da situação.

Haraway tem uma forma ainda mais provocadora de colocar a questão: devemos construir relações de parentesco com outros seres, animados e inanimados, se quisermos efetivamente caminhar no tratamento dos problemas ambientais.

No contexto dos conflitos associados ao Antropoceno, dois exemplos equivalentes de acordos pragmáticos são as manifestações conta a exploração de xisto betuminoso no Canadá, em 2013, e os protestos contra o oleoduto que cruzaria o território Sioux nos estados de Dakota do Sul e Dakota do Norte, nos Estados Unidos, em 2016. Em ambos os casos, viam-se pessoas indígenas marchando ao lado de estudantes universitários não-indígenas, ativistas e celebridades televisivas. Enquanto os manifestantes indígenas referiam-se à poluição do seu solo sagrado como motivação para o protesto, ativistas e celebridades gritavam o slogan de que não devemos continuar emitindo carbono. $\mathrm{O}$ fato de que um astro de Hollywood seja incapaz de entender o que é o solo sagrado Sioux não o impediu de marchar ao lado de anciãos Sioux que não têm nada parecido com a "molécula do carbono" em suas ontologias. Este é um exemplo pedagógico do tipo de acordo pragmático que precisamos no futuro.

Precisamos encontrar formas de "marchar" ao lado de processos do sistema terrestre que não entendemos, bem como de rochas, rios, plantas, animais, e outros seres humanos. É claro que isso não significa abdicar do uso da capacidade do uso da linguagem, mas apenas que devemos parar de atribuir poderes metafísicos transcendentes a ela - inclusive o de resolver todos os conflitos humanos -, e entender que a linguagem é tão material e relacional quantos as demais dimensões da existência. 
3) Nas conversas sobre o Antropoceno e a crise ambiental planetária, as palavras e ações de resistência de comunidades indígenas de distintos lugares é frequentemente evocada. Qual é, na sua visão, a contribuição que estas experiências e intervenções, aparentemente tão distanciadas da face mais tecnológica, para não dizer tecnocrática, dos discursos oficiais sobre o Antropoceno, oferecem ao debate?

São inúmeras, e possivelmente as transformações em curso relacionadas ao papel e lugar dos intelectuais e líderes indígenas nas sociedades ocidentais ou ocidentalizadas fará com que sejamos capazes de perceber nuances dos modos de existência indígenas que hoje não são valorizadas. Refiro-me, no caso do Brasil, ao fato de que, no período de dois anos, Sonia Guajajara foi candidata à vicepresidência da república, Raoni foi indicado ao prêmio Nobel da Paz, Ailton Krenak foi agraciado com o prêmio Juca Pato de intelectual do ano e Davi Kopenawa ganhou o Right Livelihood Award e foi eleito para a Academia Brasileira de Ciência. E isso tudo nos dois anos mais obscuros e retrógrados da história política recente do país.

Uma parte da resposta já foi elaborada nas questões anteriores. O que se poderia agregar é o fato de que, como Latour desenvolve em seu último livro, não se pode ficar assistindo o desenrolar dos fatos na esperança de que, no fim, tudo dê certo em razão de alguma ordem transcendente misteriosa. O momento atual é de embate entre quem se alinha e vive de acordo com as agendas de exploração colonial do planeta, mesmo que não se perceba desta forma, e quem luta pela recomposição dos modos de existência em aliança com os ecossistemas e demais seres. O discurso oficial sobre o Antropoceno está em transformação, justamente em razão do ativismo das lideranças indígenas, como Davi Kopenawa ${ }^{15}$ e Ailton Krenak ${ }^{16}$, e dos pensadores que venho mencionando em minhas respostas, junto aos meios mais conservadores da ciência e da sociedade. E uso o termo ativismo de forma consciente aqui: não se trata de escrever livros e esperar que o mundo se transforme (ou não) como resultado. A disputa se dá palmo a palmo, reunião a reunião, e o final

\footnotetext{
15 Kopenawa, Davi e Bruce Albert, A Queda do Céu: Palavras de um Xamã Yanomami. São Paulo: Companhia das Letras, 2015.

${ }^{16}$ Krenak, Ailton. Ideias para adiar o fim do mundo. Editora Companhia das Letras, 2019; Krenak, Ailton. O amanhã não está à venda. Companhia das Letras, 2020.
} 
da história não está definido. Esta atitude se alinha mais com o modo como os indígenas entendem a realidade do que com o pensamento ocidental moderno.

Uma última coisa que vale a pena adicionar, aqui, diz respeito à questão da relação entre os modos de vida indígena e a sustentabilidade. É possível que toda a argumentação que eu apresentei aqui até agora tenha pouca aceitação e repercussão entre os cientistas que definem isso que a pergunta chama de "discursos oficiais". Ocorre, no entanto, que pesquisas nas áreas de biodiversidade e ecologia têm mostrado que nos territórios indígenas em que as populações vivem de modos tradicionais, a eficácia na conservação da biodiversidade é igual, e algumas vezes maior, do que as medidas preservacionistas mais misantrópicas, como as chamadas áreas de proteção integral. Isto tem chamado a atenção dos biólogos e ecologistas, graças ao trabalho de antropólogos como a Manuela Carneiro da Cunha, o Mauro Almeida, o Eduardo Brondízio e outros ${ }^{17}$. Os povos indígenas, deste modo, são bons em conservação da natureza, mesmo que não tenham, em seus vocabulários, uma palavra para natureza. É de importância central, para os esforços ocidentais em conservação da biodiversidade, entender como isso se passa entre os povos indígenas e demais populações tradicionais. Escrevi sobre isso recentemente ${ }^{18}$ : a chave para a compreensão deste fenômeno reside na relação entre o conceito de cuidado e a ontologia relacional habitadas pelos povos indígenas. Colocando isso de forma direta, em um contexto em que as coisas importantes do mundo são pessoas, isto é, possuem intenção e agência, independente do formato e da natureza dos seus corpos, as relações entre os seres passam a ser sociais e políticas e, portanto, perigosas e complicadas. A liberdade de ação é bem menor em um mundo em que árvores, rios e animais são gente com força de ação política. O resultado líquido disso é o que chamamos de proteção da biodiversidade.

Ou seja, índio não protege a natureza porque gosta ou vive dentro dela; índio protege a floresta justamente porque a natureza, da forma como o Iluminismo europeu plasmou o conceito, simplesmente não existe ${ }^{19}$. Disso tudo decorre que o

\footnotetext{
17 IPBES. 2019. Summary for policymakers of the global assessment report on biodiversity and ecosystem services of the Intergovernmental Science-Policy Platform on Biodiversity and Ecosystem Services. Edited by S. Díaz, J. Settele, E. S. Brondízio E.S., et al. Bonn, Germany: IPBES secretariat. ${ }^{18}$ Taddei, Renzo. "Kopenawa and the Environmental Sciences in the Amazon." In Philosophy on Fieldwork: Critical Introductions to Theory and Analysis in Anthropological Practice, edited by Nils Ole Bubandt and Thomas Schwarz Wentzer. London: Routledge, no prelo.

19 Para uma análise surpreendente da importância filosófica do pensamento ameríndio, especialmente o de Davi Kopenawa, ver Valentin, M.A. Extramundanidade e Sobrenatureza. Florianópolis: Cultura e Barbárie, 2018.
} 
cuidado para com a vida é um precipitado da arquitetura ontológica dos mundos indígenas, sem demandar voluntarismo nem culpa. Nos modos de vida ocidentais, cuidado é entendido como vontade, como obrigação moral ${ }^{20}$, em um contexto em que as infraestruturas e o jogo político são capazes muito facilmente de desarticularem tal voluntarismo. Isso explica a desconexão entre o conhecimento e o cuidado nos modos de vida ocidentais modernos. Se tomarmos a Amazônia como exemplo, é muito fácil perceber que nunca se estudou tanto o bioma amazônico como nos últimos 20 anos; ao mesmo tempo, isso não deteve em nada a devastação da floresta. A mensagem relevante, aqui, e que é bastante contundente, é que ao invés de ficarmos culpando o mundo da política por impedir que o conhecimento científico se transforme em cuidado efetivo para com o meio ambiente, precisamos transformar as bases ontológicas sobre as quais conhecimento sobre o mundo e ação no mundo ocorrem, de modo que, à maneira dos mundos indígenas, conhecer seja, ao mesmo tempo e de forma imediata, cuidar.

\section{4) O seu trabalho toca frequentemente em questões associadas à} interdisciplinaridade, um tema recorrente em muitas das iniciativas relacionadas ao Antropoceno e às mudanças climáticas. Como você resumiria sua experiência e posição a respeito disso?

Com minha colega Sophie Haines ${ }^{21}$ desenvolvi uma análise das relações interdisciplinares na academia, com base nas coisas que mencionei em meu comentário acima sobre o consenso, a linguagem e a comunicação. O universo da cooperação interdisciplinar é permeado por conflitos de todas as naturezas, mas o mais proeminente é o resultado da ideia de que a colaboração só é possível com o alinhamento dos conceitos. A quantidade de tempo, fundos e amizades que se desperdiçam na tentativa vã de colonizar as mentes uns dos outros é imensa. Por essa razão as paredes simbólicas dos departamentos universitários são tão grossas. Uma forma de pensar o problema, usando ainda o arcabouço conceitual da filosofia da ciência, é considerar que em termos epistemológicos, o mundo ao qual a atividade intelectual se refere pode ser dividido em três campos: o das variáveis, foco da atenção e do investimento da atividade científica, e que define os próprios

\footnotetext{
${ }^{20}$ Puig de la Bellacasa, M. 2017. Matters of Care: Speculative Ethics in More Than Human Worlds. Minneapolis: University of Minnesota Press.

${ }^{21}$ Taddei, Renzo, and Sophie Haines. "Quando climatologistas encontram cientistas sociais: especulações etnográficas sobre equívocos interdisciplinares." Sociologias 21.51 (2019).
} 
contornos disciplinares; o dos axiomas, que são suposições a respeito da realidade que não estão ali para serem testadas, mas para instrumentalizar o trabalho com as variáveis; e o que Pierre Bourdieu ${ }^{22}$ chamou de doxa, o fundo fenomênico da realidade que é tomado como não problemático (e portanto não tem o privilégio de se transformar em variável de pesquisa), e que algumas vezes sequer é reconhecido como existente. O problema nas relações interdisciplinares é que o que é variável para uma disciplina é parte da doxa para a outra, o que induz os acadêmicos a pensar que o que os colegas de disciplinas muito distintas fazem é inútil e perda de tempo. Vivi isso na pele, no início de minha pesquisa de campo de doutorado, quando disse a colegas meteorologistas que iria pesquisar a dimensão cultural do clima. Um deles me falou que parecia óbvio que as culturas reagissem aos climas, e isso portanto não justificaria uma pesquisa que pudesse ser chamada de científica.

Hoje, mais de duas décadas depois, as grandes agências financiadoras internacionais, como a National Science Foundation e o Belmont Forum, exigem a participação de cientistas sociais em pesquisas sobre questões ambientais. As coisas caminharam. Mas falta muito a ser feito ainda.

5) Em algo que pode ser visto como um gesto "revisionista", Bruno Latour recentemente afirmou que o declínio acentuado na confiança pública das ciências "duras" e nos cientistas pode estar de alguma forma relacionado com décadas de trabalhos críticos produzidos pelas ciências sociais. Devemos nós, pesquisadores das ciências sociais (e, de forma mais geral, intelectuais) recuarmos para uma forma de "essencialismo estratégico"? Ou, colocando de outra maneira, o que significa hoje um posicionamento crítico no debate sobre o Antropoceno?

Na minha percepção, a ideia de essencialismo estratégico é produto de formas essencialistas de pensar. Como se tivéssemos uma resposta rígida e correta que precisasse ser escondida. Em termos pragmáticos as coisas podem parecer assim, mas conceitualmente a questão é outra. A ideia de que estamos escondendo a resposta “correta” vai contra a compreensão da realidade como constituída de forma

${ }^{22}$ Bourdieu, Pierre. Esquisse d'une théorie de la pratique. Précédé de trois études d'ethnologie kabyle. Le Seuil, 2018. 
relacional. É como se na arena de embates a realidade não estivesse sendo plasmada ali mesmo, mas o conhecimento sobre a realidade fosse algo rígido que é apresentado na arena como arma para acabar com a conversa. Este é um argumento antigo de Latour; já estava em Jamais Fomos Modernos²3.

Há uma outra questão importante a ser mencionada: Latour é nada mais do que vítima do seu próprio sucesso em ganhar um grau de atenção que se estende de forma inédita para fora da academia. Ele não foi o primeiro a revelar que os mecanismos de produção da ciência ocidental não condizem com a imagem que os discursos hegemônicos da ciência apresentam de si. Isso já estava em Wittgenstein. Paul Feyerabend desenvolveu toda a sua carreira sobre essa questão. O trabalho sobre os paradigmas e revoluções científicas de Thomas Kuhn 24 teve grande repercussão no mundo acadêmico, e é um dos golpes mais devastadores no positivismo. Lyotard 25 inaugura o que ficou conhecido como momento pósmoderno com um livro que ataca os ideais positivos da modernidade. Mais recentemente, a ideia de que se pode associar os problemas políticos com os científicos, de modo que ao resolver os últimos se resolvem os primeiros, foi novamente atacada pela teoria da sociedade do risco de Beck ${ }^{26}$ e da ciência pósnormal de Funtowicz e Ravetz ${ }^{27}$.

A diferença da atuação de Latour é que ele efetivamente buscou interlocução fora da academia. Ele escreveu obras teatrais, organizou diversas exposições, interagiu de forma criativa com artistas, fez experimentos sobre sua ideia de parlamento das coisas misturando intelectuais, ativistas e artistas, e recorrentemente faz uso de um estilo de escrita que busca ser inteligível entre audiências não acadêmicas. Ele começou sua carreira docente na França em uma escola de engenharia, e tem interagido de forma intensa com o meio da arquitetura e do design, especialmente no campo da computação. Ainda que para muita gente as ideias dele não são exatamente fáceis, não há dúvida de que todo o seu esforço deu frutos. E colocou ele na mira dos conservadores, naturalmente.

Ocorre que, ao se adotar uma abordagem ontológica relacional, composicionista, como ele mesmo chamou-a, não faz muito sentido pensar que os debates são

\footnotetext{
23 Latour, Bruno. Jamais fomos modernos. Editora 34, 1994.

${ }^{24}$ Kuhn, Thomas S. A estrutura das revoluções científicas. Editora Perspectiva, 2020.

25 Lyotard, Jean-François. A condição pós-moderna. J. Olympio, 1998.

${ }^{26}$ Beck, Ulrich. Sociedade de risco: rumo a uma outra modernidade. Editora 34, 2011.

${ }^{27}$ Funtowicz, Silvio, and Jerry Ravetz. "Ciência pós-normal e comunidades ampliadas de pares face aos desafios ambientais." História, ciências, saúde-Manguinhos 4.2 (1997): 219-230.
} 
vencidos em função do valor de verdade absoluta dos enunciados. Faz muito mais sentido colocar atenção nas estratégias e efeitos pragmáticos de cada debate do que defender uma ideia a ferro e fogo, independentemente de quem sejam os interlocutores. Se tudo é político, como nos mostram o feminismo, os estudos sociais da ciência e da tecnologia, a filosofia da ciência e tantos outros campos de pensamento, é politicamente irresponsável assumir uma atitude positivista sobre o mundo, ainda mais em um momento de transformação tão difícil.

Mas não é só isso. Existem arenas de debate em que o contexto e a lógica de organização semiótica da interação podem desfigurar, de antemão, uma ideia. Lyotard falou sobre essa questão em seu livro Le différend ${ }^{28}$; o grupo de antropólogos da linguagem e da semiótica vinculados aos trabalhos sobre metapragmática de Michael Silverstein ${ }^{29}$ também trabalhou extensamente sobre o assunto. Em cada momento da luta política, os avanços se dão através de alianças e movimentos cuidadosamente construídos, em função do caminho que se está seguindo, e não de alguma lógica metafísica transcendente. É assim que se caminha, honrando as alianças e caminhando devagar, com a certeza de que o próprio caminhar transforma as perspectivas.

Vou dar um exemplo mais concreto: um bocado do que vai ocorrer no que diz respeito ao meio ambiente daqui a vinte anos está sendo definido nos assentos de cursos universitários no presente. Ocorre que as pessoas ocupando os assentos dos cursos de ecologia, biologia e afins têm menos poder neste processo de plasmar o futuro do que as que ocupam os assentos dos cursos de engenharia, direito, economia e agronomia. Se quisermos que o sistema de agricultura extensiva baseada em monocultura e agrotóxico deixe de existir, não basta este debate ocorrer nos cursos ligados à ecologia e às humanidades. Ele tem que ocorrer nos cursos de agronomia. O mesmo se dá com relação à mineração ou a questões energéticas e os cursos de engenharia, a questões ligadas aos direitos ambientais e das populações tradicionais e os cursos de direito, e a ideia de crescimento econômico e os cursos de economia. Dito isso, se eu chegar em um curso de engenharia com as ideias da Haraway sobre simpoiése e materialismo sensível, no mínimo não serei tomado a sério. É nisso que as alianças e movimentos têm que ser estratégicos. Não há nada

\footnotetext{
${ }^{28}$ Lyotard, Jean-François, Le différend, Paris, Éd. de Minuit, 1983

${ }^{29}$ Silverstein, Michael. "Metapragmatic discourse and metapragmatic function" In Lucy, John ed. Reflexive language: Reported speech and metapragmatics. Cambridge University Press, 1993
} 
mais importante, hoje, do que fazer este debate sobre o Antropoceno, da forma como os autores que eu mencionei aqui o entendem, nas faculdades de engenharia, economia, direito, agronomia e outras; mas para que eu possa fazer isso, preciso construir alianças dentro destas comunidades. E estas alianças, vistas de longe e sem a compreensão da dimensão estratégica do movimento, podem parecer retrocesso ou essencialismo estratégico. Uma diferença importante aqui é que, no caso de essencialismo estratégico, não existe a abertura para efetivamente escutar quem está do outro lado da interlocução. Em uma abordagem relacional de cunho composicionista, as alianças implicam, no mínimo, a escuta mútua, e isso tem o poder de transformar os membros da aliança. É essa abertura à vida e à transformação, característica das ontologias relacionais, que está ausente na ideia de essencialismo estratégico.

Voltando então ao Latour, o que me parece que ele está tentando fazer, em seus últimos dois livros, é reordenar a dimensão metapragmática dos debates internacionais, ou seja, reordenar os marcos de referência usados pelas pessoas para dar sentido aos problemas correntes. Um bocado de gente existe em uma situação de inércia com relação aos sistemas e infraestruturas dominantes - em como consomem ou votam, por exemplo - mas que estão potencialmente (cosmo)politicamente alinhados com o que ele chama de "terranos". Seu objetivo é tirar estas pessoas de sua inércia perceptiva e afetiva, através do reordenamento simbólico dos elementos que organizam o debate. Ao mesmo tempo, Latour reconhece que não se trata apenas de ideias e regras de interação: instituições e infraestruturas são elementos fundamentais da composição dos mundos, e que precisam ser transformados. Daí a quantidade imensa de atividades extraacadêmicas às quais Latour se dedica.

Talvez mais controvertido até do que esta questão do essencialismo estratégico é o movimento recente de insistir na necessidade de composição de um mundo comum. Essa defesa da composição do mundo comum é entendida por muitos como um retrocesso com relação às ideias de multiverso e multinaturalismo, de Viveiros de Castro. Talvez seja, uma vez mais, uma desaceleração e um desvio de percurso, no intuito de construir alianças importantes que demandam essas ações. Veremos. O debate está em curso. 


\section{6) Como você vê o futuro próximo dos estudos sobre o Antropoceno e,} de maneira geral, das questões ecológicas no mundo lusoparlante e, em particular, no Brasil? Há novos projetos no horizonte que gostaria de mencionar? Que formas de intervenção são possíveis nos debates, não apenas dentro da academia mas também em níveis políticos mais amplos?

Há muita coisa acontecendo; não há dúvida que estamos em um momento de grandes transformações. Por essa razão, é muito difícil fazer previsões.

A condição do meio ambiente no Brasil, no governo Bolsonaro, é calamitosa, e não há qualquer sinal de que as coisas irão melhorar nos dois anos que ainda faltam para as próximas eleições. O país está à deriva. É impressionante, no entanto, que o país seja capaz de permanecer à deriva sem que tudo termine em anomia. Isso significa que existe alguma coisa além das estruturas de governo e do estado. É preciso seguir lutando, com todas as forças, para tirar o Bolsonaro do poder, e ao mesmo tempo é preciso abandonar o culto à figura do presidente que existe no Brasil. A situação atual do Brasil é paradoxal porque, ao mesmo tempo que aos sofrimentos trazidos pela pandemia se somam os sofrimentos trazidos por este governo, a vitalidade da sociedade civil, dos movimentos sociais e do ativismo ambiental é imensa.

Aqui acho que podemos fazer aqui um paralelo com uma das dimensões da questão do Antropoceno: ele pegou o mundo ocidental de surpresa, o que significa que há coisas bem à nossa frente que não somos capazes de perceber por muito tempo. Se assumirmos o início do Antropoceno com as detonações nucleares da década de 1940, vão-se aí mais de 70 anos e ainda não há reconhecimento científico institucionalizado sobre o fato. Não faz sentido dizer que já "se sabia" de sua existência porque Arrhenius tinha falado sobre isso em 1896. Uma voz perdida nos salões acadêmicos não pode ser tomada como percepção coletiva da realidade. $\mathrm{E}$ nem se pode reduzir o tempo que demorou para o reconhecimento do problema ao negacionismo, de forma anacrônica. O fato é que as ciências do sistema terrestre nos mostram que há inúmeros padrões de variação no funcionamento do planeta que não conhecemos, e que nos afetam diretamente. Até a década de 1920, a ciência não conhecia o fenômeno El Niño, que afeta o clima do planeta inteiro. Certamente há muitos El Niños que ainda não conhecemos, e alguns que nunca seremos capazes de conhecer com o aparato cognitivo que possuímos. O mesmo ocorre com fenômenos sociais. Há transformações e padrões no funcionamento das 
coletividades que não conhecemos, mas a que estamos sujeitos. Coisas imprevistas ocorrem o tempo todo no mundo social. No Brasil, por exemplo, ninguém anteviu as manifestações de 2013, e tampouco previu tamanho reconhecimento público e projeção das lideranças indígenas no país neste ano de 2020. Nem que este seria o ano em que, pela primeira vez na história brasileira, haveria mais candidatos pretos e pardos do que brancos nas eleições municipais. Eu sinceramente pensei que não veria isso acontecer nesta vida.

Por isso acho improdutivo reduzir o contexto brasileiro atual ao Bolsonaro. Isso é seguir cultuando o estado, de certa forma, e reproduzir uma visão de mundo antropocêntrica. Há coisas importantes, inclusive nas dimensões tradicionalmente chamadas de sociais, que não acontecem na escala dos indivíduos nem na escala dos estados. Esta é exatamente uma das dimensões do Antropoceno. Reconhecer isso talvez diminua a amargura e a negatividade com que a intelectualidade progressista brasileira tem observado a realidade.

Em termos do que se vê no horizonte, o quadro é confuso, mas gosto de manter a minha atenção voltada aos fatos que sugerem que mudanças positivas estão ocorrendo. Vejamos: a ONU tem um secretário geral efetivamente comprometido com a agenda ambiental, e está sinalizando em direção à inclusão de indicadores ambientais nos índices usados para avaliar a situação dos países, como o IDH. O Papa Francisco é um ambientalista de esquerda. Trump perdeu as eleições nos EUA, e isso pode ter efeito cascata sobre a política no resto do mundo. A pandemia, a despeito da dimensão impensável de sofrimento que trouxe, forçou os mecanismos de governança planetários a se redesenharem e melhorarem seus processos. Mostrou ainda que a colaboração científica pode ocorrer sem ser induzida, e deformada, pela competição capitalista. A pandemia também deixou bastante evidente a necessidade da luta pelos comuns, inclusive entre grupos mais conservadores. As elites conservadoras abandonaram, por exemplo, a ideia de privatizar o sistema público de saúde brasileiro, o maior do mundo.

No Brasil, enquanto a ciência e a universidade são estranguladas pelo governo atual e resistem bravamente, os movimentos sociais, as periferias, a arte de rua e as iniciativas de solidariedade associadas à pandemia demonstram uma energia impressionante. O movimento da agroecologia tem ganhado muita força no país, também. Acho que, no curto prazo, haverá mais avanço vindo dessas áreas do que da academia. Mas coisas importantes estão ocorrendo no campo acadêmico, 
também. O que me está mais próximo é a experiência dos bacharelados interdisciplinares, nos quais efetivamente há um esforço de superação das barreiras disciplinares no tratamento de questões importantes. Sou professor em um bacharelado interdisciplinar em ciência e tecnologia do mar, onde os estudantes são preparados para lidar com as questões ambientais a partir de suas dimensões físicas, ecológicas, mas também filosóficas e sociológicas. Esta tem sido uma experiência muito positiva, e que me ajuda a ter esperança sobre o futuro.

Recebido em: 24/12/2020. Aprovado em: 26/12/2020. Publicado em: 26/12/2020. 